\title{
II.-THE NATURE OF INCOMPATIBILITY.
}

\author{
Bi Leslie J. WaLkER.
}

THE Ontological Argunent for the existence of God as stated by Leibnitz, differs in an important respect from all previous stafements of it : it is based upon the nature of incompatibility. 'We have the idea of God,' Anselm had said, 'as a Being comprising in Himself all perfections ; therefore, since existence is ${ }^{\circ}$ perfection and without it God would not comprise all perfections, He must exist.' ' This our ides of God as comprising in Himself all perfections, is clear and distinct, said Descartes, "hence, since clearness and distinctness is the criterion of objective validity, God exists.' The conclusiveness of these arguments as they stood Leibnitz denied, while at the same time readily granting that he had an ides of God such as his predecessors had described, and also that this idea, if not self-oontradictory, must be objectively valid, since it included as one of its notes 'necessary existence'. He urged, however, that an essential step in the argument had been omitted. His illustrious predecessors had neglected to prove that the attributes of God were compatible. If God is possible, He certainly exists; but is $\mathrm{He}$ possible? "The Ontological Argument is not a paralogism, but an imperfect demonstration, which presupposes something that it is still necessary to prove to give the argument mathematical evidence ; namely, it is tacitly supposed that this idea of the all-great and all-perfect Being is possible, and implies no contradiction." 1

This presupposition Leibnitz set himself to prove. $\mathrm{He}$ begins by defining what he understands by a Being who has all perfections simpliciter, and then gives his proof of the compatibility of all simple and positive perfections. "I call a perfection every simple quality that is pusitive and absolute and expresses without any limits whaterer it does express. Now, since such a quality is simple, it is als . irresolvable or

'The Philoxphl! "f Ireilmit?, Russell, p. 286 (G r..419). 
indefinable, for otherwise it will either not be one simple quality, bat an aggregate of several, or, if it is one, it will be circumscribed by limits and will therefore be conceived by a negation of further progress, contrary to the hypothesis, for it is sssumed to be purely positive. Hence it is not difficult to show that all perfections are compatible inter se, or can be in the same subject. For let there be such a proposition as $A$ and $B$ are incompatible

(understanding by $\mathrm{A}$ and $\mathrm{B}$ two such simple forms or perfections-the same holds if seversl are assumed at once), it is obvious that it cannot be proved withont a resolution of one or both of the terms A and B ; for otherwise their nature would not enter into the reasoning, and the incompatibility of any other things could be shown just as well as theirs. But by hypothesis they are irresolvable. Therefore this proposition cannot be proved concerning them." 1

Thus incompatibility, according to Leibnitz, holds only between positive and negative terms (between $A$ and not-A), or between a positive idea (A) and some complex idea involving the negation of the first ( $B$ resolvable into $B^{\prime}$ and not- $A$ ). For we bave no immediate and necessary judgment of incompatibility, or, as Leibnitz puts it, ' the incompatibility of $A$ and B is not true per se,' and consequently can be shown only by a process of reasoning. This reasoning, however, cannot be synthetic, since the synthesis of two or more ideas will not reveal their incompatibility unless they have first been analysed; hence, it must he analytic. But simple.ideas cannot be anslysed, and so 'cannot enter into the reasoning'. All simple and positive ideas, therefore, must be compatible.

This proof of the compatibility of all simple perfections is based upon the theory that incompatibility can always be reduced to contradiction. Mr. Russell, on the other hand, while conceding that positive and negative ideas are necessarily incompatible, thinks that there may also be incompatibility between positive idess. "Thus a self-contradictory ides, if it be not a mere negative, such as a non-existent existent, must always involve a synthetic relation of incompatibility between two simple notions. The impossible ides in Leibnitz's sense, presupposes the ides which is impossible on account of some synthetic proposition; and conversely, the possible complex ides is possible on account of a synthetic proposition asserting the compatibility of its simple constitaents." :

'The Philosophy of Leibrits, Rnssell, p. 287 (G vii, 281).

I Itul., p. 21. 
In Mr. Russell's opinion, therefore, simple ideas are not always compatible or 'reconcilable among themselves'. Consequently the legitimacy of their combination in complex ideas will depend upon 'synthetic relations of compstibility and incompatibility'. Thus in definition there is always presupposed " the synthetic proposition that the simple constituents are compatible"; while, on the other hand, but for "synthetic relations of incompatibility no negative proposition would occur". 1 With neither of these statements can I agree. It sems to me that there is no such thing as a relation of incompatibility between simple ideas, and that negation presupposes, not incompatibility, but limitation. And one way of establishing this opinion in regard to the nature of simple ideas will be to remove all foundation for these synthetic relations of incompatibility, by showing that all incompatibility can be reduced to contradiotion, and this is the thesis which I shall endesvour to prove.

The points, therefore, which I wish to make, are as follows: (1) That of compatibility we have immediate knowledge through the analysis of the various complex wholes presented to consciousness; (2) that negation presupposes individual objects which differ from one another, and that the negative judgment is primarily our way of expressing the fact that a quality belonging to one object does not do facto belong to another ; (3) that belief in positive incompatibility is bssed npon repested experiences of qualities which never coexist in the same object, and is thus at first empirical in nature; (4) but that an examination of these qualities which do facto are never found together in the same object, reveals the further fact that they are mutually contradictory and so necessarily inoompatible.

In the first place, then, the function of-the intellect is to apprehend the nature of reality-to reproduce in the individual consciousness more or less completely and more or less adequately the universe of which it is a part. The humsn intellect, however, is incapable of apprehending in a single act the universe as a whole. It has perforce to build up its knowledge, beginning with the individual. The individual is itself complex, indeed; but at first it is presented as a whole, a unity, a 'thing'. By outline, movement, unity of action, we easily distinguish it from the background, and gradually by comparing it with other things we learn to analyse it into its qualities or attributes. "Not only must each object present itself to as integrally before it shells off

1 The Philosophy of Leibnits, Russell, pp. 20, 21 pawim. 
into its qualities, but the whole scene around us must disengage for us object after object from its still background by emergence and change; and even our self-detachment from the world over against us must wait for the start of collision between the force we issue and that we receive. To confine ourselves to the simplest case: when a red ivory ball, seen for the first time, has been withdrawn, it will leave a mental representation of itself, in which all that it simultaneonsly gave us will indistinguishably coexist. Let a white ball succeed to it; now, and not before, will an attribute detach itself, and the colour by force of contrast, be shaken into the foreground."

Thus, by analysis, we learn that different qualities do in fact belong to the same object, and from this may legitimately infer-what is already implicitly recognised-that they can belong to the same object, or, in other words, that they are compatible. A posse ad esse valet illatio. Knowledge of compatibility thus presupposes nothing beyond the mental analysis of a concrete whole into its differentiating parts or qualities. ${ }^{2}$

Our knowledge of incompatibility stands on a different footing. Inference from the actual to the possible is valid a fortioni; but we cannot infer that what is not actual is impossible. And incompatibility is the impossibility of coexistence in the same object. Hence the mere absence of co-existence is strictly no proof of incompatibility.

Before discassing, however, the nature of that incompatibility which we believe to hold between certain positive qualities, it will be well to treat of the incompatibility of contradictories, since this in our theory is the fundamental form of incompatibility. Our belief in the incompatibility of contradictories is expressed in the Principle of Contradiction. How, therefore, and when, we may ask, does belief in this principle arise? Is it due to an immediate and necessary judgment? Or is it-like the ordinary man's belief in the incompatibility of positive qualities-based merely upon experience?

Let us return for a moment to Dr. Martineau's example of the white and red balls. Suppose that these balls are placed before us side by side, or, better still, that they are moving slowly in opposite directions. We shall now distinguish not merely two colours, but two objects, the one white and the other red. Suppose, further, that some one removes the balls,

1 Martinean, Foniys Plit. and Theol., vol. i., p. 271-2.

= Cf. F. H. Bradley, Appearince anil Reality, p. 569 . "As a fact and given we have in feeling diversity and unity in one whole." 
and then places one in our hand without letting us see it. Something perhaps suggests that it is the white one, and prompts us to form the judgment: 'This is the white object'. But, when we look, we find that it is the red one that has been given to us. Another judgment will now take the place of the one at first suggested, and we shall say, "This is not the white object, but the red one'.

In some way such as this, and at a very early stage in the child's mental development, I conceive that the negative judgment arises. The negative judgment is essentially one in which o suggested predicate is rejected. ${ }^{\downarrow}$ It is doubtless true, as Mr. Bradley says, that in negation the idea denied " in every case qualifies an alternative more or less distinct; and hence nowhere floats absolutely".: For instance, if we assert that 'a square circle does not exist,' 'existence' is certainly a possible predicate of reality ; and so is 'possibility' if we change the form of our proposition and say that 'a square circle is impossible'. But the essential characteristic of the negative judgment is its rejection of a suggested predicate. And this rejection is possible only because objects are limited, and have not the predicates which are suggested as belonging to them.

The negative judgment, moreover, always involves an implicit recognition of the Principle of Contradiction. Negation would be meaningless if this were not the case. When we say 'This object is not white' we imply that the corresponding affirmative must be false. The law that contradictories are incompatible is essential to the intelligent use of negation. Thus even a child, when it forms a negative judgment, may be said implicitly to recognise the validity of this fundamental principle of thonght. For, though the child would probably not understand an explicit formulation, since this would presuppose considerable development in its powers of abstraction, yet it can hardly be said in no sense to understand a principle which it actually uses and without which its judgments would be meaningless.

Whether, then, we say that 'the same thing cannot at the same time be and not be', or that 'affirmation and denial are

\footnotetext{
'Plato's statement in the 'Sophistes' that, when we speak of notbeing, "we speak not of something opposed to being, but only different" wonld seem to identify negation with 'otherness'. And it is true in one sense that " the not-beautiful is the contrast of being with being," since the not-beantiful has a positive implication. But the primary and essential meaning of the not-beantiful is the negation of beauty. Negation may involve otherness, but the two idess are not identical.

'F. H. Bradley, 'On Floating Idess and the Imaginary,' MIND, N.S., 60, p. 449.
} 
incompatible,' the law of thought thus formulated has all the marks of a self-evident trath. In either form it compels our assent; it is involved in one of the fundamental forms of thought-the negative judgment, and unless it were valid thought would be impossible ; also its contradictory is inconceivable. Moreover, apart altogether from the question as to whether origin affects validity, in as much as the Principle of Contradiction is involved, and in fact used, in the very first negative jadgment that we make-and even this judgment must mesn something -it would hardly seem to be the result of experiment, as Mr. Schiller asserts, or of experience, as Mr. Husik would put it. Indeed, both the Progmstist and Empirical account of its origin appear to me to be due to an ignoratio elenchi. Mr. Schiller tells us that " the Principle of Contradiction may be taken as simply the negative side of that of Identity;" 1 and the Principle of Identity is understood by him to affirm " the persistence of Identity through change " ; " so that the Pragmatist formulation of the Principle of Contradiction must be somewhat as follows: "A thing must be capable of excluding whatever threatens (the persistence of) its identity (through change)".? But this is certainly not the Principle which we claim as an axiom or self-evident truth. The axiomatic and traditional Principle of Contradiction says nothing at all about persistence or change. It restricts itself to one and the same moment of time. It is quite probable that belief in the persistence of objects through change is due to experience and experiment, but this belief is a very different thing from our belief that an object cannot at the same time and in the same sense be and not be.

Nor is Mr. Hasik's attack on the axiomatic nature of the Principle any more to the point. For, convinced that it is learnt by experience, he prefers to enunciate it in his own way, viz.: "A thing cannot have at the same time what experience finds it cannot have at the same time". To the principle as thus enunciated, I am disposed to object in the first place, that experience alone is incapable of finding what an object can or cannot have at the same time. Experience, in the sense in which Mr. Husik appears to be asing the word, can tell us what things do or do not have at the same time, but questions as to possibility or impossibility are of a higher order than mere experience. In the second place, granted that belief in incompatibility does arise whenever two or more

1 'Arioms as Postulates,' Pernonial Iderliom, p. 108.

2 Ibid., p. 98. 'Ibid., p. 106.

t'Aristotle and the Principle of Contradiction,' MIND, N.S., 58, p. 215. 
qualities are found never to co-exist, yet this incompatibility is between positive qualities, while the Principle of Contradiction asserts incompatibility between affirmstion and denial, or between the positive idea 'being' and its corresponding negative 'not-being'. A certain amount of experience is doubtless wanted before we recognise that white objects cannot at the same time be red ; but we recognise that the statement ' This is not $X$ ' means precisely the opposite of the statement ' This is $X$ ' and the consequent incompatibility of the two statements, contemporaneously with the first intelligent use of negation.

The principle of contradiction is based, therefore, on the natare of affirmation and denial, and would thas seem to belong primarily to the logical order. But this does not make it merely subjective, for it is also based upon certain facts of the objective order. Negation itself presupposes that objects are limited, one having or being what another has not or is not; for, otherwise, there would be nothing to deny. Negation, in fact, would be impossible unless (1) there were relatively independent objects (or at least qualities), each having a certain determinate nature of its own; and unless (2) these objects differed from one another; and (3) it were possible to get to know their respective natures. Since then the principle of contradiction presupposes Negation, it presupposes indirectly these objective facts, and so is capable of an objective or ontological interpretation. Yet, though the statement that 'the same thing cannot at same time be and not be' has meaning, it is really only the objectification of the principle that it is impossible intelligently to affirm and at the same time to deny. Such terms as 'not-being,' 'nothing,' 'unreal,' 'impossible,' are not true concepts; for, in abstraction from their positive correlatives, they have no meaning. They signify merely the negation of the corresponding positive terms objectified. It is only in exceptional cases that we use them as subjects of intelligible propositions, and when used as predicates, they constitute in reality a negative judgment.

It will be interesting, if we may digress for a moment from the problem before us, to compare the principle of Contradiction with the so-called Principle of Identity. As traditionally enunciated, the Principle of Identity states that 'Whatever is, is'. But how this enunciation is to be defended against the charge of tautology-if taken, as the words naturally imply, in the objective sense-I have never boen able to see. Moreover, as this Principle claims to be a Law of Thought, it should, as a 'Law,' state a relation 
between different things, and, as a 'Law of Thought,' be expressed in logical terms. If, on the other hand, we interpret the principle to mean that 'Fverything has a determinate nature,' or, that there is such a thing as 'Identity in Difference," this again is hardly a law of thought; nor is it any longer the complement of the Principle of Contradiction, as it purports to be; for the latter is a necessary law, or a law stating a necessary connection between things, wheress the Principle of Identity, if such be its meaning, is merely 'positive'. Again, if we say that "it is possible to make judgments that have a meaning and are true," " though we have now a statement about a process of thought, yet, again, the law, so stated, is little more than descriptive, and seems to belong to the psychological, rather than to the logical order; for, unlike the Principle of Contradiction and all other logical laws, it has no normative application as a guiding principle of cognitive operations. It seems to me, therefore, that the Principle of Identity has no claim to be regarded as a logical principle at all, nor indeed as a law in the same sense that the Principle of Contradiction is a law, unless we take it merely as another way of expressing the Principle of Contradiction itself, viz., that what objectively is, cannot be treated in thought as if it were not.

So far we have discussed only one kind of necessary incompatibility, that which holds between affirmation and denial. But there are other kinds. Many positive qualities never co-exist in the same object; and repeated experience of this fact generates in as the belief they are incompatible. Is this incompatibility a mere fact, or is it a necessity? Must we, in the case of these positive qualities, be content with mere empirical knowledge, or can we go further and attempt to explain their apparent incompatibility? Contradiction andoubtedly involves incompatibility; is it equally true to say that incompatibility involves contradiction?

That incompatibility does involve contradiction, and is therefore a necessity and not a mere fact is what we have to prove, if we are to establish Leibnitz' assertion that simple ideas are never incompatible; for his a priori proof, as it stands, is hardly convincing. And I think that it can be proved, for it can be shown in many cases that of incompatible qualities one is implicitly the negation of the others, and hence of necessity cannot belong to the same object.

Aristotle treats incompatibility under the name of ' $\mathrm{Op}$ position,' and it will be convenient, in further discussing its

'Bosanguet, Logic, vol, iio, is 208. 'Ibil, p. 207. 
nature, to use his classification. "Things are said to be opposed to one another in four ways; as Relatives, as Contraries, as Privation and Possession, and as Affirmation and Denial. For example, the double and the half are opposed as Relatives; bad and good as Contraries; blindness and sight as Privation and Possession; ' $\mathrm{He}$ is sitting' and ' $\mathrm{He}$ is not sitting' as Affirmation and Denial." 1

The opposition which exists between Affirmation and Denial is expressed in the Principle of Contradiction, and of this we have already treated. It may, as we have seen, and as Aristotle himself points out, be taken in an objective as well as in a purely logical sense. Not only is ' $\mathrm{He}$ is sitting' opposed to 'He is not sitting,' but the objects to which the predicates 'sitting' and 'not-sitting' refer, are also opposed."

Of the four kinds of Opposition, we are told in the Metaphysics that Contradiction is the 'first' - a term which from the context evidently means the most fundamental, or that on which the other forms are based. ${ }^{3}$ The passage is thus commented on by Aquinas: "Of these four kinds of opposition the first is contradiction. And the reason is this, that contradiction is involved in all the others as something more fundamental (prius) and more simple. For it is impossible that opposites of any kind should exist together in the same object, and this is due to the fact that one opposite by its very nature implies the negation of the other.'

That the second kind of opposition can be reduced to the first requires little proof. "For privation means either the complete incapacity to possess (a certain attribute), or the non-possession of an attribute which a thing is naturally fitted to possess, the one being complete privation, the other privation that is in some way limited." $"$ In fact, privation in general is defined as 'negatio in aliquo subjecto'. Wherefore the opposition of privation and possession is, as Aristotle says, a kind of contradiction.

The reduction of contraries to contradiction, on the other

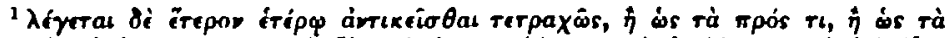

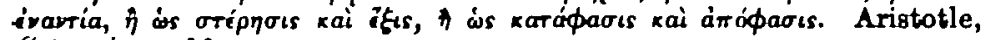
Cintegories, c. 10.

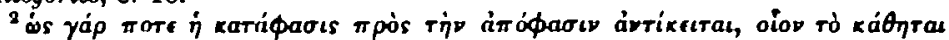

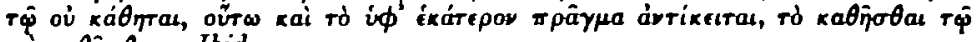

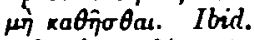

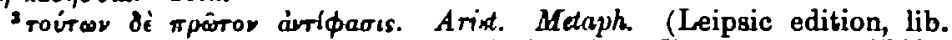

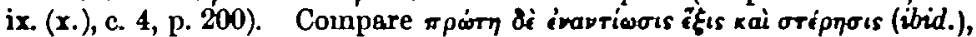
where again $\pi \rho$ irt is used in the sense of the most fundamental, or that from which all other forms are derived.

- Commentaria in A rist. Metaph., lib. x., lect. 6.

${ }^{3}$ Metaph., lib. ix. (x.), c. 4, pp. 200, 201. 
hand, is by no means so simple a matter, since contraries admit of a mean, whereas contradiction does not. The difficulty is, however, only apparent and will admit a satisfactory explanation. In the first place, it is always possible to find some larger class to which a given pair of contraries belongs. Contraries, in other words, are of the same genus, and in it

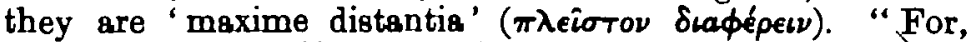
since things that differ may differ to a greater or less extent, there will always be a greatest difference and this I call Contrariety." 1 Contraries thus constitute the two extreme differentio of a given genus, between which there may be many 'means'.?

In the second place, the differentim of a genus may be regarded as giving fuller meaning or fuller reality to the genus which they differentiate, inasmuch as they enlarge or perfect the generic notion by the addition of other notes. One of the extreme differentiæ or contraries will thas give to the genus its highest or final perfection; for instance, the genus animal reaches its highest perfection in the human organism. Taking, then, this perfection as an ideal standard, we may arrange the other differentio in a scale according to the degree in which they approach this ideal. ${ }^{3}$ We shall thus have a maximum and a minimum, the maximum being the ideal perfection itself, and the minimum the limiting case where there is a nataral sptitude in regard to the perfection in question, but no proximate disposition or approach towards its realisation. These maxima and minima are the contraries, and are seid to constitute the first differences of the genus, because we may consider the 'means' as arising from their. combination in various proportions.

Hence, we may regard a differentis in two ways, either as a specific difference which gives a certain determination or form to the genus and so constitutes the species; or as a mere stage in a process which bas for its end the realisation of a certain ideal perfection. It is in this second sense that the extreme differentio are contrary to one another. For "the contrariety existin between the differentiæ of a genus

\footnotetext{
'There is one exception: 'corruptible' and 'incorruptible' are con. traries, but do not fall under any of the 'summa geners' or categories mentioned by Aristotle. They are said 'per se dividere ens'; and 80 , like the categories themselves, they are not predicable univocally of ens. That they are inutually contradictory, however, is evident from their torm. lf. Matapli. ix. (x.), c. 10.

Ibil., c. 4.

'This 'ideal 'perfection sccording to Aristotle and Aquinas seems to have been regarded as the greatest actural perfection, so that for him contraries constitute the greatest cot ual difference.
} 
is considered according to the common principle upon which contrariety is based, namely, excellence and defect ${ }^{1}$. Thus contrariety involves intensive quantity. And this applies not only to the extremes but also to the 'means'. In fact, any pair of differentim may be regarded as contraries relative to those differentix which lie between them. Every differentia, then, has a certain intensive quantity which will depend apon the degree in which it realises the ideal perfection of the maxima differentia. And it is on account of this intensive quantity that the incompatibility of positive qualities arises.

Here for the third time, therefore, we come across that fundamental characteristic of individusl objects which we found to be presupposed by the possibility of negation and of contradiction, vis., limitation. This limitation may be either qualitative or quantitative; but in a sense all limitation involves quantity. An object may be limited in that it has certain qualities whereas others are absent, and it may also be limited in that it has these qualities only in a certain degree; both of which cases imply quantity, though in a different way. Moreover, our knowledge of objects includes the knowledge of their limitations. We do not study things in isolation; we compare them; and so learn that their qualities are limited both in number and degree; and this limitation is implied in the definition which we may give of them.

Thus all definition has a negative as well as a positive aspect. We mean by a man, a cow, a newspaper, a triangle, objects having (1) certain qualities, and not others; and (2) a certain degree of these qualities, and no more. Now, either an object has a certain quality or it has not. If, then, by calling it a cow we affirm certain qualities of it, and by call. ing it a horse we implicitly deny them, we have contradicted ourselves. Again, either an object has or it has not a certain determinate degree of some perfection. If, then, red implies one degree of this perfection and blue another, red and blue are mutaally contradictory and for this reason incompatible; since by predicating one degree of a perfection we implicitly deny any other. It is only between contraries as contraries that there is a mean, in as much as it is posaible that an object may have neither the maximum nor the minimum of the quality in question. But, in so far as it has a certain degree of that quality, it cannot have at the same time any other degree. In other words, when we have determined the degree of perfection which an object has in the genus to

'Aquines, Comment. in A rist. Phyricn. lib. v., lect. 3. 
which it belongs, to assign to it any other differentia of that same genus would involve contradiction. The same thing can belong to one species only. Hence, all the differentim of a genus are necessarily incompatible, and this incompatibility is besed on the Principle of Contradiction.

It remains to confirm this law by a few examples before passing on to a brief consideration of the fourth kind of incompatibility, that between relatives. Positive incompatibility is found to hold chiefly between the sensible qualities of objects. Hot and cold, hard and soft, rough and smooth, we infer from sense-experience to be incompatible. Each of these pairs of opposites, moreover, belongs to the same genus, and between them there are means, so that they are contraries. Thus, temperature, hardness, and roughness, vary in intensive quantity and admit of degree. Again, temperature is due to molecular movements varying in length: hardness to resistance varying in intensity; roughness and smoothness to the spatial arrangement of the resisting points, which may be at a greater or less distance from one another on a given surface. Hence the incompatibility of different degrees of heat and coldness, roughness ana smoothness, hardness and softness, respectively, is explained by the fact that each pair of contraries and the means lying between them involve different intensive quantities of the same fundamental property or quality. Thus, their incompatibility is based upon contradiction; and this conclusion, inferred first of all from perceptual data, is confirmed by our knowledge of the objective nature of the qualities perceived.

The incompatibility of tastes and odours would seem to be due to a similar cause; for we find contrast, compensation and degree in sweetness, saltness, acidity, bitterness, as well as in various smells. As, however, there is no satisfactory classification in smells, and even in taste it is impossible as yet to arrange the four primsry taste-qualities in pairs so as to form a scale, the incompatibility which they evince cannot actually be reduced to contradiction; though from the data above-mentioned, the inference as to the nature of their incompatibility is at least probable.

In treating of colours we are on surer ground. In spite of the fact that introspective data present many difficalties, and have given rise to several different theories, yet even our present knowledge, imperfect as it is, affords a striking confirmation of the theory we have been advancing. In the frat place, there are complementary colours and their mixtures, giving us grar.uated series; red through white to green, yellow through white to blue, white through grey to black. 
Then there is the spectrum, where the positive colour qualities arrange themselves in a scale according to their refractive indices. Finally, there is the undalatory theory of light, which reduces colours to different rates of vibration and different lengths of ether waves, as in the case of heat. All this is so much evidence pointing to the conclusion that different colours are but different intensive quantities of some fundamental quality or mode of motion. True, the subjective data and the physical theory are not yet completely coordinated, but both show at any rate this, that colour involves quantity or degree - a fact which in itself is sufficient to prove that contradiction is the basis of the incompatibility of colours.

I might add indefinitely to the examples I have chosen, for if contraries are the first specific differences of a genus, there will be as many pairs of contraries as there are genera, and in each case the incompatibility of two or more attribates will result. But the principle involved and the method of reducing the incompatibility to contradiction will be the same. Let us proceed, then, to consider relative opposition.

"Things which are relatively opposed are said to be what they are on account of their being opposites, or on account of their being in some way different from one another " $;$ in other words, it is precisely on account of the relation holding between them that they get their respective names. Thas, a man is said to be a 'father' in reference to something other than himself, and on account of a certain relation other than that of identity, holding between himself and that other thing, his 'son'. The same may be said of the correlative 'son,' and similarly for other pairs of relatives, e.g., the 'double' and the 'half.' Since, then, "things that are relatively opposed are said to be what they are in reference to other things, or on account of their relation to other things," ? the incompatibility of relatives is only a special case of the incompatibility of relations in general.

How does this incompatibility of relations arise? Things are said to be related in virtue of their attributes; thus, one book is 'like' another in virtue of its colour, or its binding, and 'smaller' than another in virtue of its extensive quantity or size. These attributes, moreover, on account of which the relation is predicated, are not considered in isolatiun, but in comparison with an attribute of some other thing. A relation

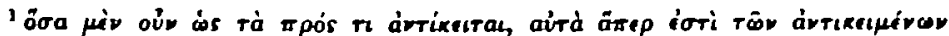

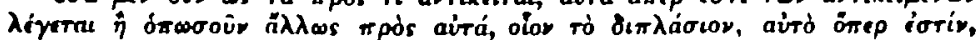

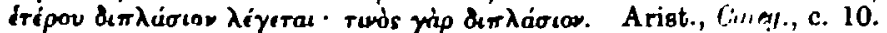

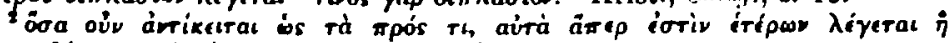

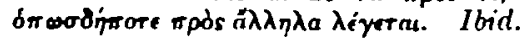


is essentially a mpós $\tau \iota \sigma \chi \chi^{\prime} \sigma \iota s$, a reference of one thing to another, and the relation is predicated or said to exist in virtue of certain attributes belonging respectively to the two things. The attributes on account of which the relation is predicated are, therefore, essential to the relation. Change either of them and you change the relation, which depends for its existence upon their being what they are. And conversely for a new relation to be predicable or for a given relation to change, the terms must change.

Let us suppose now, that two different relations are predicated as holding simultaneously between two objects. If the attributes in virtue of which these relations are predicated, and in virtue of which they differ, are incompatible, the relations also will be incompatible. Incompatibility of relations thas arises from incompatibility of attribates. But the incompatibility of attributes is due, as we have seen, to some kind of quantitive incompatibility, and so is reducible to contradiction. Hence the incompatibility of relations and of relatives is also reducible to contradiction.

Thus, for material things to occupy different places, or to be of different sizes and shapes at the same time, is impossible, because in each case extrinsic or intrinsic space-relations are involved; and space-relations imply quantity, since they imply that given points in the object in question are at certain definite distances from an indefinite number of other points within or without the object, distance being measured by extensive quantity. Again, to say that ' $A$ is the father of $B$,' and at the same time 'the son of B,' is implicitly a contradiction, as may be shown in several ways. For instance, both $A$ and $B$ are individuals occupying a determinate place in the time-series and in the natural order. This time-series may be represented by a line, part of which corresponds to the life of $\mathrm{A}$ and part to the life of $\mathrm{B}$; the line, moreover, being such that, at any point $X$, it will be divided into two parts, antecedents and non-sntecedents (or consequents). Now, the assertion that ' $A$ is the father of $B$,' fixes the point $X$, and determines $A$ (in virtue of part of his life at any rate) as an antecedent, and $B$ as not an sntecedent, and, in this sense, the opposite or contradictory of $A$; and the statement that ' $B$ is the father of $A$,' or ' $A$ the son of $B$,' would reverse the respective positions of $A$ and $B$ in this time-series. $B$ would now be an antecedent, and $A$ not an antecedent; which is evidently a contradiction of what was involved in the previous statement that ' $A$ was the father of $B$ '.

We have now discussed under the four headings suggested by Aristotle, the various kinds of incompatibility of which 
we have experience. Two of these, affrmation and denial, possession and privation, are obviously contradictory in nature. Our belief in the other two, the incompatibility of contraries and of their means, and of relatives, on the other hand, is based primarily on the fact that such attributes and relations never co-exist. And though from non-co-existence we cannot legitimately infer incompatibility, it would appear, nevertheless, that this quasi-instinctive belief of mankind is not fallacious. For, while positive qualities, and the relations which depend upon them, are not incompatible in so far as they are positive, yet, since they are limited both in number and degree, and limitation always has a negative implication, this incompatibility does of necessity arise. Incompatibility thas involves and can be reduced to contradiction.

The theory of incompatibility upon which Leibnitz beses his Ontological Argument would, therefore, seem to be valid. Between positive qualities as such, incompatibility cannot exist. Positive and simple attributes, onless they are "circumscribed by limits," and so in a sense negative as well as positive, are always compatible. " Ea quae non sunt opposita, possunt simul existere in eodem." 1

But, having granted the validity of this theory, are we forced to accept the Ontological Argument itself as valid? Whatever our ultimate decision may be, there are several objections which demand consideration. I shall des w with them under three heads. In the first place, it is often said that the Ontological Argument involves an illicit transition from the ideal to the actual order; secondly, it may be objected that existence is not a predicate; and, thirdly, it may be urged that we have all along been dealing with 'created' perfections, and that we cannot infer from the compatibility of these to the compatibility of the attributes of God-and this is the only objection which seems to me to be of any resl force.

1. In regard to the alleged illicit transition from the ideal to the actual, it would seen that although in general 'a posse ad esse non valet illatio,' this dictum does not apply to the case of God. If we define God as the 'Necessary Being,' there can be no question of an illicit transition ; for the concept of what is possible (can be), and at the same time is necessary (cannot not be) must be objectively valid, otherwise the concept would be contradictory. But, suppose we define God as an Infinite Being, or a Being who comprises in Himself all simple perfections in an infinite degree. is the infer-

${ }^{1}$ Aquinas, Comment. in Metaph, lib. x., lect. 10. 
ence 'a posse ad esse' equally valid? Does Infinity imply Necessary Existence? Leibnitz speaks of God indifferently as an Infinite Being and as a Necessary Being; and the two terms are really equivalents. For an Infinite Being cannot receive $\mathrm{His}$ existence from anything else, since $\mathrm{His}$ infinity excludes the possibility of anything else existing independently of Him. In other words, whatever else exists must be wholly dependent upon Him for its existence, and so cannot give Him existence. An Infinite Being, therefore, must exist ' a se,' of itself ; that is, its existence must proceed from itself and be necessarily involved in its other attributes, which are such that it cannot not exist. Hence, if God is possible, $\mathrm{He}$ exists. But, in proving the possibility of God, we must not forget that the existence which we predicate of Him, is Necessery Existence or Self-sufficiency, and the possibility of this must be shown. The question as to how far we have proved the possibility of God in this sense, I shall discuss under the third objection.

2. Mr. Russell admits that on the analytic theory of necessary judgments, Leibnitz' argument proves that God, as defined by Leibnitz, is possible. But he objects to the Ontological Argument itself, which is involved in saying that, since existence is a perfection, God exists. "This," he says, "depends upon regarding existence as a predicate, which Lueibnitz does," . . . wheress " he ought to have arrived at Kant's position that existence is not a predicate, and that God's non-existence cannot be self-contradictory." 1

Personally I must admit that the Kantian argument regarding existence as a predicate does not convince me. I see no objection to admitting that "a hundred thalers which I merely imagine," are not " exactly like a hundred thalers. which really exist". For, to predicate existence of them, though it does not change their essential nature, yet makes a real difference in the ides which I form of them. "Existence" has meaning. 'Existing things' are not the same as 'things in the abstract'; they have a power of affecting me and my consciousness in a way which is impossible to things that do not exist. Consequently the addition of the idea of 'existence' to the idea of 'thalers' gives the latter a meaning which they had not before. My idea of 'existing thalers' and my idea of 'thalers in the abstract' are not exactly alike.

3. Since, then, existence has meaning, and since we do not actually predicate it intelligently, I am disposed to admit

${ }^{1}$ The Philisophy of Leihiti, hassell, p. 174-5. 
that it is a predicate. But, on the other hand, existence, when predicated of God, is predicated in a different way to that in which it is predicated of anything else. Of God, we predicate 'Necessary Existence,' while of other things we predicate only 'contingent existence'. And the two kinds of existence, or the two ways of predicating existence are only anslogous; i.e., we cannot in the strict sense of the words make existence a genus of which 'necessary' and 'contingent' are the differentiæ.

Now, all that our argument as to the nature of Incompatibility has proved, is that 'contingent existenoe' is compatible with simple attributes such as we know them in rerum natura: or, granting that it is possible to regard existence in abstraction from its necessity or its contingency-that 'existence in the abstract' is compatible with such attributes. But this is insufficient for the purpose of the Ontological Argument. God is essentially a Necessary Being, and npon this depends the validity of the major: 'If God is possible, He exists'. Hence, to prove that God is possible, we must show how existence is implied in His other attributes, or-to put the same thing in another way - we must prove that Necessary Existence is compatible with these attributes: for it makes all the difference to the validity of our argument whether the existence we predicate is necessary or not.

This our theory of incompatibility certainly does not prove. Moreover, another difficulty of a similar kind suggests itself. We have been dealing throughout with beings that are both contingent and limited, and have shown that, when their attributes are incompatible, they involve contradiction; and hence we have inferred that simple and positive attributes as such cannot be incompatible. But are the simple qualities which we have examined, at all comparable with the attributes of God? At best the comparison is only that of analogy. And though the proof may hold in regard to all simple natures as such, and although simple natures as such are not limited in degree, yet the analogy weakens the argument when it is applied to attributes predicated of God. ${ }^{1}$ Again, the attributes with which we have been dealing are of

\footnotetext{
1 The assertion of analogy does not mean that there is no similarity between contingent perfections and the attributes of Gind, or that the former are not truly manifestations of the latter. But the attributes of God are not separable in kind ; they are all involved in His Deity ; so that contingent perfections, such as goodness and wixdom, are not predicable of God in the same sense that they are predicable of creatures, but only in an analogous sense. Iet it is neverthe's; srue that "by an accumulation of such analogous predications we approximate towards the ever unattainable comprehension of Deity".
} 
the physical order, and, even granting that we may legitimately infer the nature of incompatibility, so demonstrated, to be nniversal, yet it will be by no means an easy task to ahow that moral attributes, such, for instance, ss Justice and Mercy, are not mutually contradictory. And further, granted that Justice is the truest Mercy, and that other moral attributes are similarly compatible, we have still to show that the predication of these attributes is not a contradiction of the Unity of God. How is the synthesis of all thase attributes in one Being possible? We cannot say. The theory of Incompatibility that we have been advocating, does little more than show that the compatibility of God's attributes cannot be disproved. It is sufficient merely to throw the onus probandi on an opponent.

Thus Leibnitz' view of the nature of incompatibility does not seem to complete the Ontological Argument. It supplies an obvious deficiency, bat there is still something further required, a step in the process of reasoning which has not yet been proved, and which it would seem to be impossible to prove without infringing upon the province of other arguments. At the same time it will be admitted, I think, that the famous proof of the Existence of God, when supported by this theory of Incompatibility, if not conclusive, is at least a strong presumptive argument well deserving attention and having distinct religions value as a motive to belief. We cannot, indeed, show a priori iny necessary connection between God's attributes, yet the fact that even among con. tingent existents, their "qualities are not, as in Bacon's view, put together as ingredients are inserted to constitute a dish, but are different aspects of one and the same central arrangement," 1 would seem to point to a necessary connexion and to mutual implication.

There are also other versions of the Ontological Argument besides that of Anselm, Descartes, and Leibnitz. Nicholas de Cusa, for instance, urges that, anless the concept we form of Infinite Being is objectively valid, all knowledge and all science is mesningless. For, "all things seek the same which is something absolute". The modern argament besed on the ideals of which we are conscious and on the need which we feel of their ultimate satisfaction, is similar. Expressed in this form as a postalate for which we seek verification, the argament has much more force, especially in the philosophicel atmosphere of the present dey; for, unless these ideals are realised somewhere, our nature and needs aro without meaning and withont purpose.

1 Venn; Empirional Logic, p. 82. 
To these and indeed to all proofs of the existence of God, this theory of Incompatibility is, I take it, of value. For, to many minds, the suspicion thst the simple and infinite attributes under which God is conceived may be incompatible, suggests that our conception of Him, so far from being real, is impossible; and that hence, all arguments advanced to prove His existence are worthless; while the synthetic theory advocated by Mr. Russell, contains an implicit difficulty in regard to the Unity of God; since, if I have understood Him aright, it involves a fundamental Duslity, two systems of being or beings specifically and essentially incompatible, and of which there cannot possibly be a single common Ground. If, on the other hand, we grant that incompatibility is due to contradiction, and that contradiction presupposes negation, and negation objects limited in nature, objections against attributes that are not limited in natare but infinite, cannot be arged on the ground of any incompatibility, such as wo can conceive. This view is, I think, in harmony with that of modern Hegelians, though I have considered it from the Realist rather than from the Idealist standpoint. Mr. Bradley tells us that there are 'no native contraries' or incompatibles. "Things are contrary (incompatible) when, being diverse, they strive to be united in one point which in itself does not admit of internal diversity." " He adds, however, that " conjunction and contradiction in short is bat our defect, our one-sidedness, and our abstraction, and it is appearance and not Reality". Here I must beg to differ. Of the nature of conjunction and Compatibility, of the problem as to how different qualities can belong to the same object, I have said nothing; but, in my view, though there are no native incompatibles, yet incompatibility and contradiction are both founded in Reality, viz., in the reality of limited objects, dependent on God, but relatively independent. of one another.

'Bradley, Appercrince and Reality, p. 672. 